Original Research Article

\title{
Evaluation of antidiabetic activity of Tinospora cardifolia in alloxan induced diabetes in albino wistar rats
}

${ }^{1}$ Department of Pharmacology, Basaveshwara Medical College \& Hospital, Chitradurga, Karnataka, India ${ }^{2}$ Department of Pharmacology, SDM College of Medical Sciences \& Hospital, Dharwad, Karnataka, India

Received: 06 May 2018 Accepted: 30 May 2018

\section{*Correspondence to:}

Dr. Ravi K. Sori,

Email: soriravi@gmail.com

Copyright: (C) the author(s), publisher and licensee Medip Academy. This is an openaccess article distributed under the terms of the Creative Commons Attribution NonCommercial License, which permits unrestricted noncommercial use, distribution, and reproduction in any medium, provided the original work is properly cited.

\author{
Abhijith L. M. ${ }^{1}$, Ravi K. Sori ${ }^{2 *}$
}

\begin{abstract}
Background: The objective was to evaluate the antidiabetic activity of Tinospora cardifolia in alloxan induced diabetes in albino rats in comparison with a currently used oral hypoglycaemic glibenclamide.

Methods: there were 24 rats with FBS in the range $80-115 \mathrm{mg} / \mathrm{dl}$ were selected for the study. Four groups each containing six rats, were induced diabetes with alloxan $(150 \mathrm{mg} / \mathrm{kg})$. The diabetic control group $(0.5 \mathrm{ml}$ normal saline), Standard control group $(5 \mathrm{mg} / \mathrm{kg}$ glibenclimide), Test group I $(200 \mathrm{mg} / \mathrm{kg}$ T. cardifolia $)$ and test II group $400 \mathrm{mg} / \mathrm{kg}$ T. cardifolia). FBS was recorded on 1, 3, 7, 14, 21 and $28^{\text {th }}$ day using glucometer. Data was analysed by using one way ANOVA and posthoc Tukey's test SPSS 21Version.

Results: Extract of Tinospora cardifolia showed dependent hypoglycaemic action in both low dose $(200 \mathrm{mg} / \mathrm{kg}$ ) and high dose group $(400 \mathrm{mg} / \mathrm{kg})$. Hypoglycaemic action with high dose of Tinospora cardifolia is comparable to that of standard drug glibenclamide.

Conclusions: This study demonstrates the hypoglycaemic action of $T$. cardifolia in diabetic rats. $T$. cardifolia can be a therapeutic potential to treat type 2 diabetes mellitus.
\end{abstract}

Keywords: Alloxan, Glibenclamide, Hypoglycaemia, Tinospora cardifolia

\section{INTRODUCTION}

Diabetes mellitus is a group of metabolic diseases characterized by hyperglycaemia resulting from defects in insulin secretion, action or both. ${ }^{1}$

Once regarded as a single disease entity, diabetes mellitus is now seen as heterogenous group of diseases characterized by hyperglycaemia resulting from various causes. ${ }^{2}$ The chronic diabetes is associated with long term damage, dysfunction and various organ failure especially eyes, nerves, heart, kidneys and blood vessels. ${ }^{3}$

Various drugs are being used in the treatment of diabetes mellitus but search for more effective drugs with fewer side effects is on, as an alternative the herbal extracts and products are on the list for evaluation as there is a huge history of herbal drugs used in various diseases entities. ${ }^{4}$ So, objective of this study is to investigate the anti-diabetic activity of root extract of Tinospora cardifolia and its comparison with currently used oral hypoglycaemic agent glibenclamide. 


\section{METHODS}

Chemicals used in the study was alloxan monohydrate, Glibenclamide hydrochloride, Sodium chloride and extract of Tinospora cardifolia.

Animals were 24 Albino rats of $180-220 \mathrm{gms}$ of either sex.

Equipment's were used during the study were mouth gag, polythene feeding tube, syringe, blood drawing pipettes and glucometer.

\section{Plant preparation and extraction}

The fresh roots were purchased from the local market and the roots of $T$. cardifolia were shade dried and coarsely powdered. The powder is filled in to filter paper bag and placed ilaced in the soxhlet apparatus for extraction. The soxhlet apparatus is connected to round bottom flask which is fill by ethanol (90\%) solvent and water bath to maintain temperature. The ethanol was boiled at $40^{\circ} \mathrm{C}$ for over a period of 24 hours. The extract obtained was $10 \%$ and was stored in desiccator at room temperature. ${ }^{5}$

\section{Experimental animals}

The animals were taken from central animal house male/female albino rats of albino strain, weight - 200$250 \mathrm{gms}$. The animals were housed under standard condition, housed individually with normal water and food granules, 12:12 hours light dark cycle, $50 \%$ humidity and $28^{\circ} \mathrm{C}$ temperature and provided with standard food granules and water ad libitum

Fasting blood glucose readings were recorded in all rats after an overnight fasting. Blood samples were obtained from retro-bulbar technique, after ether anaesthesia. Blood glucose was estimated by using glucometer. The rats with FBS in the range $80-112 \mathrm{mg} / \mathrm{dl}$ were selected for the study.

\section{Induction of diabetes}

Table 1: Rats were divided in to six treatment groups, 4 rats in each group.

\begin{tabular}{|c|c|}
\hline Group & Drug \\
\hline NDCG- Non diabetic control group & $0.5 \mathrm{ml}$ of $\mathrm{NS}$ \\
\hline NDTG- Non diabetic test group & $\begin{array}{l}100 \mathrm{mg} / \mathrm{kg} T . \\
\text { cardifolia }\end{array}$ \\
\hline DCG- Diabetic control group & $0.5 \mathrm{ml}$ of $\mathrm{NS}$ \\
\hline SC- Standard control & $\begin{array}{l}\text { Glibenclamide } \\
0.5 \mathrm{mg} / \mathrm{kg}\end{array}$ \\
\hline Test-I - Diabetic test group I & $\begin{array}{l}100 \mathrm{mg} / \mathrm{kg} T . \\
\text { cardifolia }\end{array}$ \\
\hline Test-II - diabetic test group II & $\begin{array}{l}200 \mathrm{mg} / \mathrm{kg} T . \\
\text { cardifolia }\end{array}$ \\
\hline
\end{tabular}

Alloxan monohydrate was used to induce diabetes mellitus, after an overnight fasting, the rats were injected with freshly prepared $2 \%$ solution of alloxan monohydrate in $0.9 \%$ normal saline. The dose injected was $150 \mathrm{mg} / \mathrm{kg}$ body weight. Following injection, animals were observed for 24-48 hours for evidence of any allergic reaction, behavioural changes and convulsions. Fasting blood glucose was estimated at around 9:30 AM daily until stable hyperglycaemia was established. Rats which developed a stable hyperglycaemia with FBS of more than $200 \mathrm{mg} / \mathrm{dl}$ were selected for the study. ${ }^{6}$

- Group I- Non diabetic control group: This group received $0.5 \mathrm{ml}$ of NS daily for 30 days.

- Group II- Non diabetic test group: This group received $100 \mathrm{mg} / \mathrm{kg} \mathrm{T}$. cardifolia extract daily for 30 days.

- Group III- Diabetic control group: This group received $0.5 \mathrm{ml}$ of NS daily for 30 days.

- Group IV- Standard control: This group received glibenclamide $0.5 \mathrm{mg} / \mathrm{kg}$ suspended in $0.9 \%$ NS daily for 30 days.

- Group V- Diabetic test group I: received $100 \mathrm{mg} / \mathrm{kg}$ T. cardifolia extract daily for 30 days.

- $\quad$ Group VI- Diabetic test group II: received $100 \mathrm{mg} / \mathrm{kg}$ T. cardifolia extract daily for 30 days.

In all the groups the blood glucose levels were recorded on day $-1,3,7,14,21$ and $28^{\text {th }}$ day.

\section{Statistical analysis}

The results will be analysed using one way ANOVA in SPSS 21 Software for Microsoft. The statistical significant value for any measure was set to $\mathrm{p}<0.05$ at a confidence interval of $95 \%$. The results expressed is in mean \pm standard deviation.

\section{RESULTS}

In this study, the blood glucose levels of animals selected for the study was in the range of $80-115 \mathrm{mg} / \mathrm{dl}$. The mean blood glucose before induction of diabetes in all six groups varied from $94.2-103 \mathrm{mg} / \mathrm{dl}$.

Both non diabetic control group and non diabetic test group did not vary in their blood glucose level throughout the study period. For analysis of results the following groups are considered.

Diabetic control group, Standard control group, Test group-I, Test group-II.

Table 2 to Table 7 give statistical analysis of the results on day $1,3,7,14,21$ and 28 by using one way ANOVA followed by post hoc turkey's test. The $p$ value $<0.05$ was considered significant.

On day 1 , there was significant difference between test group II compared to DCG, SC, Test I. 
On day 3, there was no significant difference between any groups except for the comparison of standard control group with test II group.

On day 7, there was statistical significant difference for the comparison of SC, DCG and Test II and no significant difference exists between rest of the groups.

On day 14, except for the comparison DCG with Test -I and SC with Test II there was significant difference between all other groups.

On day 21 and 28, the difference is maintained in all groups. On day 21 there was better glycaemic control in standard group compared to both the test groups, whereas on day 28 the glycaemic control was better with standard group, but test II shows comparable glycaemic control than test I.

Table 2 shows on day 1, there was significant difference between test groups II compared to DCG, SC, Test I.

Table 2: Comparison of blood glucose levels between different groups on day 1.

\begin{tabular}{|ll|}
\hline Groups compared & Mean difference \\
\hline 3 and 4 & 1.3 \\
\hline 3 and 5 & 38.6 \\
\hline 3 and 6 & $76.1 *$ \\
\hline 4 and 5 & 37.3 \\
\hline 4 and 6 & $74.8 *$ \\
\hline 5 and 6 & $37.5 *$ \\
\hline
\end{tabular}

Values are mean \pm SD.* - Values are statistically significant at $\mathrm{P}<0.05$ using one way ANOVA followed by Tukey's test.

Table 3 shows on day 3 , there was no significant difference between any groups except for the comparison of standard control group with test II group.

Table 3: Comparison of blood glucose levels between different groups on day 3.

\begin{tabular}{|ll|}
\hline Groups compared & Mean difference \\
\hline 3 and 4 & 54.2 \\
\hline 3 and 5 & 9.2 \\
\hline 3 and 6 & 16.1 \\
\hline 4 and 5 & 45.0 \\
\hline 4 and 6 & $70.3 *$ \\
\hline 5 and 6 & 25.3 \\
\hline
\end{tabular}

Values are mean \pm SD.* - Values are statistically significant at $\mathrm{P}<0.05$ using one way ANOVA followed by Tukey's test.

Table 4 shows on day 7, there was statistical significant difference for the comparison of SC, DCG and Test II and no significant difference exists between rest of the groups.

Table 5 shows on day 14, except for the comparison DCG with Test -I and SC with Test II there was significant difference between all other groups.
Table 4: Comparison of blood glucose levels between different groups on day 7.

\begin{tabular}{|ll|}
\hline Groups compared & Mean difference \\
\hline 3 and 4 & $104.3 *$ \\
\hline 3 and 5 & 56.2 \\
\hline 3 and 6 & 25.7 \\
\hline 4 and 5 & 48.1 \\
\hline 4 and 6 & $79.6 *$ \\
\hline 5 and 6 & 30.5 \\
\hline
\end{tabular}

Values are mean \pm SD.* - Values are statistically significant at $\mathrm{P}<0.05$ using one way ANOVA followed by Tukey's test.

Table 5: Comparison of blood glucose levels between different groups on day 14.

\begin{tabular}{|ll|}
\hline Groups compared & Mean difference \\
\hline 3 and 4 & $135.0 *$ \\
\hline 3 and 5 & 33.8 \\
\hline 3 and 6 & $85.3 *$ \\
\hline 4 and 5 & $101.2 *$ \\
\hline 4 and 6 & 49.7 \\
\hline 5 and 6 & $51.5 *$ \\
\hline
\end{tabular}

Values are mean \pm SD.* - Values are statistically significant at $\mathrm{P}<0.05$ using one way ANOVA followed by Tukey's test.

Table 6 and 7 shows on day 21 and 28, the difference is maintained in all groups. On day 21 there was better glycaemic control in standard group compared to both the test groups, whereas on day 28 the glycaemic control was better with standard group but test II shows comparable glycaemic control than test I.

Table 6: Comparison of blood glucose levels between different groups on day 21.

\begin{tabular}{|ll|}
\hline Groups compared & Mean difference \\
\hline 3 and 4 & $201.3 *$ \\
\hline 3 and 5 & $52.7 *$ \\
\hline 3 and 6 & $141.0 *$ \\
\hline 4 and 5 & $148.6 *$ \\
\hline 4 and 6 & $60.3 *$ \\
\hline 5 and 6 & $88.3 *$ \\
\hline
\end{tabular}

Values are mean \pm SD.* - Values are statistically significant at $\mathrm{P}<0.05$ using one way ANOVA followed by Tukey's test.

Table 7: Comparison of blood glucose levels between different groups on day 28.

\begin{tabular}{|ll|}
\hline Groups compared & Mean difference \\
\hline 3 and 4 & $255.5 *$ \\
\hline 3 and 5 & $79.0 *$ \\
\hline 3 and 6 & $185.7 *$ \\
\hline 4 and 5 & $176.5 *$ \\
\hline 4 and 6 & $69.8 *$ \\
\hline 5 and 6 & $106.7 *$ \\
\hline
\end{tabular}

Values are mean \pm SD.* - Values are statistically significant at $\mathrm{P}<0.05$ using one way ANOVA followed by Tukey's test. 
Table 8 shows percentage reduction in BGL in different groups on day $1,3,7,14,21$ and 28 . Standard group shows more reduction in BGL $(67.1 \%)$ compared to both the test groups (Test I -28\%) (Test II - 56.9\%) at the end of the study.

Table 8: Comparison of percentage reduction in blood glucose levels between standard and test groups.

\begin{tabular}{|lllllll|}
\hline Groups & $\begin{array}{l}\text { Day } \\
\mathbf{1}\end{array}$ & Day 3 & Day 7 & $\begin{array}{l}\text { Day } \\
\mathbf{1 4}\end{array}$ & $\begin{array}{l}\text { Day } \\
\mathbf{2 1}\end{array}$ & $\begin{array}{l}\text { Day } \\
\mathbf{2 8}\end{array}$ \\
\hline Sest-I & $4.6 \%$ & $17.8 \%$ & $30.6 \%$ & $38.3 \%$ & $56.3 \%$ & $67.1 \%$ \\
\hline Test-II & $1.8 \%$ & $10.8 \%$ & $22.4 \%$ & $17.8 \%$ & $24.1 \%$ & $28.1 \%$ \\
\hline
\end{tabular}

Table 8 shows the mean percentage reduction of Test II $(30.36 \%)$ which is comparable to that of standard group $(35.7 \%)$.

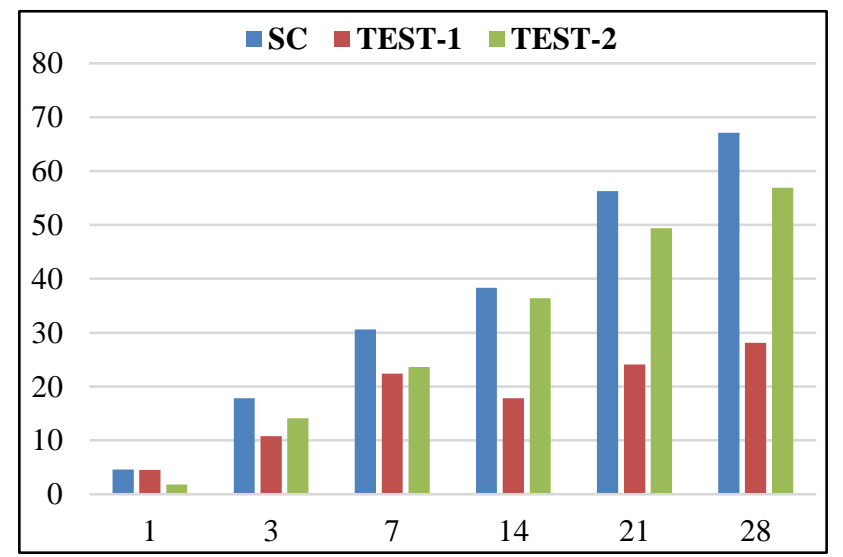

Figure 1: Percentage reduction of blood glucose levels in standard and test groups.

Table 9: Overall mean percentage reduction of blood glucose levels in standard and test groups.

\begin{tabular}{|ll|}
\hline Groups & Mean percentage reduction \\
\hline SC & $35.7 \%$ \\
\hline Test - I & $17.9 \%$ \\
\hline Test - II & $30.36 \%$ \\
\hline
\end{tabular}

\section{DISCUSSION}

The aqueous extract of stem of Tinospora cardifolia (TC), commonly known as Guduchi sattwa in Ayurveda, is recommended for the treatment of diabetes mellitus. ${ }^{7}$ Authors, therefore, preferred the aqueous extract of the root and it has been evaluated and its efficacy is compared with that of standard oral hypoglycaemic drug glibecamide. The extract met with all the analytical specifications of the standardized herbal extract as per the international standards.

In this study, low dose $T$. cardifolia $(100 \mathrm{mg} / \mathrm{kg})$ decreased blood glucose level (BGL) from $420.3 \mathrm{mg} / \mathrm{dl}$ on day 1 to $315.7 \mathrm{mg} / \mathrm{dl}$ on day 28 and high dose $(200 \mathrm{mg} / \mathrm{dl}) T$. cardifolia decreased BGL from $477.8 \mathrm{mg} / \mathrm{dl}$ to $209 \mathrm{mg} / \mathrm{dl}$ on day 28. The results show that the root extract of $T$. cardifolia has definitive hypoglycaemic activity. The present study is in accordance with the previous studies done by who reported the hypoglycaemic action of $T$. cardifolia. ${ }^{8}$

The percentage reduction in BGL during the study period is $17.9 \%$ for low dose of $T$. cardifolia $(100 \mathrm{mg} / \mathrm{kg})$ and $30.3 \%$ for high dose of $T$. cardifolia $(200 \mathrm{mg} / \mathrm{kg})$. This shows the dose dependent activity of $T$. cardifolia.

Singh SS et al, investigated the chemical constituents and the medicinal properties of ethanolic extract of Tinospora cordifolia at a dose of $400 \mathrm{mg} / \mathrm{kg}$ body weight, which produced a significant reduction of blood sugar in alloxan induced diabetic rats. ${ }^{9}$

In this study $T$. cardifolia did not produce hypoglycaemic in non-diabetic test group (BGL-115mg/dl on day 1 $100.3 \mathrm{mg} / \mathrm{dl}$ on day 28 ), which suggests that it might have anti-hyperglycaemic activity and no hypoglycaemic activity in normal rats. Studies show that $T$. cardifolia induces secretion only in the presence of high plasma glucose level which supports our above observation. This can be a huge advantage in the therapy of diabetes mellitus, since one of the important adverse effect of using conventional anti diabetic drugs is hypoglycaemia.

The study has several limitations, the study has carried out only in one species of animals viz rats and needs to be extended to other animals as well. There is a need to fix the proper dosage of $T$. cardifolia. Acute and chronic toxicity testing need to be undertaken.

\section{CONCLUSION}

Refined $T$. cardifolia extract has hypoglycaemic effect in diabetic rats and it does not have hypoglycaemic action in normal rats. The hypoglycaemic activity is comparable to that of glibenclamide in diabetic rats. Thus refined $T$. cardifolia extract could be used as an oral hypoglycaemic agent in diabetes. However extensive studies need to be done to confirm this activity in animal models as well as human trials.

\section{Funding: No funding sources \\ Conflict of interest: None declared}

Ethical approval: The study was approved by the Institutional Animal Ethics Committee (1284/ac/17/CPCSEA)

\section{REFERENCES}

1. American diabetic association. Diagnosis and classification of diabetes mellitus. Diabetic Care. 2005;28(1):S37-S42.

2. Park K. Park's textbook of preventive and social medicine. $19^{\text {th }}$ Edn. Jabalpur: Banarasidas Bhanot;2005:327-332. 
3. Kasper DL, Braunwald E, Fauci AS, Hauser AL, Longo DL, Jameson JL, editors. Harrison's principles of internal medicine, vol.2, $16^{\text {th }}$ Edn., Newyork, McGraw Hill;2005:2152-2179.

4. Babu V, Gangadevi T, Subramaniam A. Antihyperglycemic activity of cassia Kleinii leaf extract in glucose fed normal rats and alloxan induced diabetic rats. Indian J Pharmacol. 2002;34;409-15.

5. Sivakumar V, Dhanarajan MS, Hypoglycemic and antioxidant activity of Tinospora cordifolia in experimental diabetes. IJPSR. 2011;2(3):608-13.

6. Dunn JS, Mcletchie NG. Experimental alloxan diabetes in the rat. Lancet. 1943;245:484-7.

7. Krishna KL, Jigar B, Jagruti P. Guduchi (Tinospora cordifolia): Biological and Medicinal properties: A review. Internet J Altern Med. 2009;6:2.
8. Sivakumar V, Mohamed Sadiq A. Hypoglycemic Activity of Tinospora cordifolia in Alloxan induced diabetic rats. The Bioscan 2009;4(1):75-8.

9. Grover JK, Rathi SS, Vats V. Amelioration of experimental diabetic neuropathy and gastropathy in rats following oral administration of plant (Eugenia jambolana, Mucuna pruriens and Tinospora cordifolia) extracts. Indian J Exp Biol. 2002;40:273-6. [PubMed]

Cite this article as: Abhijith LM, Sori RK.

Evaluation of antidiabetic activity of Tinospora cardifolia in alloxan induced diabetes in albino wistar rats. Int J Basic Clin Pharmacol 2018;7:13826. 